\title{
Experimental Analysis and Design of Axial Flow Fan Used in an Air Cooled Heat Exchanger
}

\author{
A.Mahesh Babu ${ }^{1}$, T.V.Naveen Kumar ${ }^{2}$ E.Vigneshwar Reddy ${ }^{3}$ \\ ${ }^{I}$ (Assistant Professor, Mechanical Department,Cmr Engineering College/Jntu H, India) \\ ${ }_{2}^{2}$ (Assistant Professor, Mechanical Department,Cmr Engineering College/Jntu H, India) \\ ${ }_{3}^{3}$ (Assistant Professor, Mechanical Department,Cmr Engineering College/Jntu H, India)
}

\begin{abstract}
A heat exchanger is a piece of equipment built for efficient heat transfer from one medium to another. The media may be separated by a solid wall, so that they never mix, or they may be in direct contact. They are widely used in space heating, refrigeration, air conditioning, power plants, chemical plants, petrochemical plants, petroleum refineries, natural gas processing, and sewage treatment. The role of air flow plays vital role in heat exchanger. Presently heat exchangers use the air flow rate of 5-6 $\mathrm{m}^{3} / \mathrm{s}$ which gives less efficiency. Therefore the design of more than $7 \mathrm{~m}^{3} / \mathrm{s}$ air flow rate in the heat exchanger is done to maintain better efficiency. The required parameters of air flow fan are air flow, operating temperature, static pressure, Nominal fan speed, External diameter. The modification in existing fan was done and desired air flow optimum velocity was achieved $15.23 \mathrm{~m} / \mathrm{s}$ at circular duct and $6.675 \mathrm{~m} / \mathrm{s}$ to archive required parameters.
\end{abstract}

Keywords: Heat Exchanger, Axial Flow Fans, 1 Tube-Axial Fan, Petroleum Refineries.

\section{Introduction}

There are two general classifications of fans: the centrifugal or radial flow fan (see ED-2400) and the propeller or axial flow fan. In the broadest sense, what sets them apart is how the air passes through the impeller.

The propeller or axial flow fan propels the air in an axial direction (Figure 1.1) with a swirling tangential motion created by the rotating impeller blades. In a centrifugal fan the air enters the impeller axially and is accelerated by the blades and discharged radially (Figure 1.2).

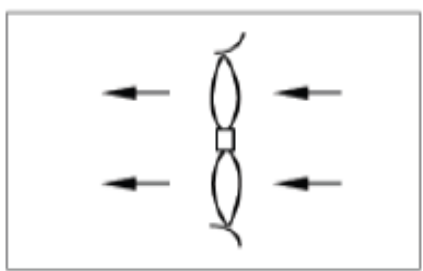

Figure 1.1 Axial Flow

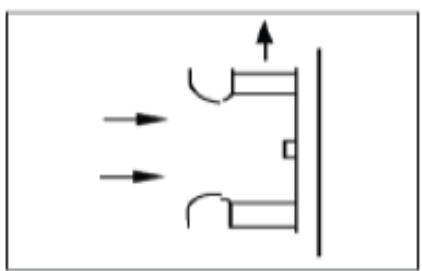

Figure 1.2 Centrifugal Flow

1.1 Axial Flow Fan: Axial flow fan is shown on fig 1.3

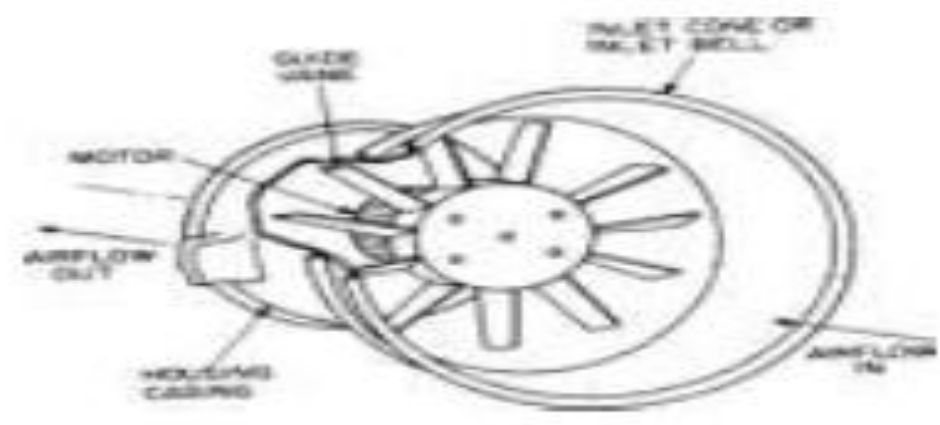

Figure 1.3: Axial flow fan 


\subsection{Axial Flow Fan Types}

Propeller Fans: Sometimes called as the panel fans, propeller fans are the lightest, least expensive and most commonly used fans. These fans normally consist of a flat frame or housing to be mounted in a wall or in a partition to exhaust air from a building. This exhausted air has to be replaced by fresh air, coming in through other openings. If these openings are large enough, the suction pressure needed is small. The propeller fans, therefore, are designed to operate in the range near free delivery, to move large air volumes against low static pressures. These fans can be built both direct drive and belt drive (Figure 1.4 and Figure 1.5).
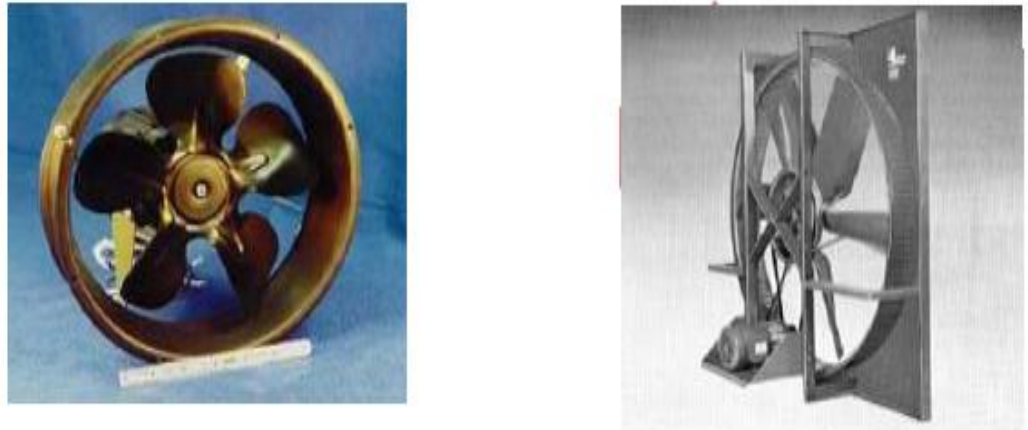

\section{Figure 1.4: Propeller fan with direct drive Figure 1.5: Propeller fan with belt drive}

\subsubsection{Tube-axial Fans}

A tube-axial fan is a glorified type of propeller fan with a cylindrical housing about one diameter long, containing a motor support, a motor and a fan wheel. The motor can be located either on upstream or downstream of the fan wheel. The fan wheel of a tube-axial fan can be similar to that of a propeller fan. It often has a medium sized hub diameter,
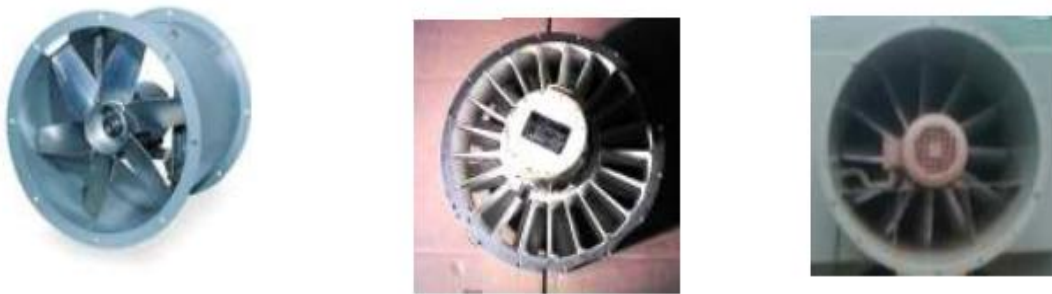

Figure 1.6: Tube-Axial Fan Figure 1.7: Vane Axial Fan Figure 1.8: Single -Stage Axial Flow Fan

\subsection{Performance of Axial Flow Fans}

Figure 1.9 shows the shape of a typical pressure versus flow rate curve. Starting from the free delivery, the pressure value rises to a peak value. This is the good operating range for an axial flow fan. As the air volume decreases due to increasing restrictions, the axial air velocity decreases as well, resulting in an increased angle of attack and increased lift coefficients (the phenomena can be understood better in Chapter 2). The increase in the lift coefficient is responsible for the increase in the pressure. After the maximum lift angle is reached, the flow can no longer follow the upper contour of the blades, thus separate from the surface of the blade. Separated flow results in a decrease in lift coefficient, thus a decrease in pressure occurs.

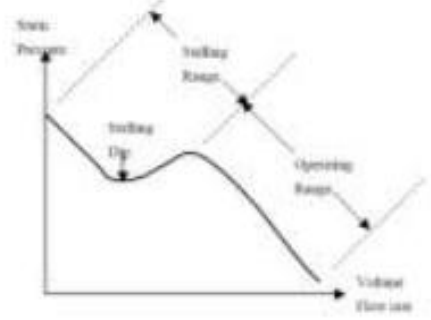

Figure 1.9: Static Pressure vs. Volume flow rate of an axial fan [24]. 


\subsection{Heat exchangers}

Heat exchanger geometry and area are constant by definition in the fixed plant simulations. However, changes to fluid flow rates will affect the fluid flow regime, equipment operating pressures, and temperature differences throughout each heat exchanger; which in turn will affect fluid physical properties. Changes in the fluid flow regime were assumed to have a greater affect on the overall heat transfer coefficient than changes in fluid properties (viscosity, density, heat capacity, and thermal conductivity).

\subsection{Material Selection}

\section{Material Selection \& Experimental Setup}

In air cooled heat exchanger as they exposed to changing climate condition, the control of the air in the cooler is relevant. The problem exists in the fan provided in the heat exchanger available in Patel Heat Exchanger, Pvt. Limited, Govindpura, and Bhopal. It was given the air flow at the rate $5.944 \mathrm{~m}^{3} / \mathrm{s}$ where as it was required for efficient cooling at the rate $7 \mathrm{~m}^{3} / \mathrm{s}$ is above. The design of the fan was done and after proper fabrication the fan was tested for the desired rate of air flow. The following design considerations were taken into account to modify the design of the fan.

1. External diameter $\left(\mathrm{d}_{2}\right)$ of the axial flow fan

2. Internal diameter $\left(\mathrm{d}_{1}\right)$ of the axial flow fan.

3. Rotational speed (n).

4. Angle of Blade at enter $\left(\beta^{\mathrm{o}}{ }_{1}\right) \&$ discharge $\left(\beta_{2}^{\mathrm{o}}\right)$.

5. No. of Blade (z)

6. Shape \& aerofoil section of the Blade.

In the design of single stage axial flow fan, the speed is mainly adapted to the choice of the driving machine, therefore especially for electrical driver, the speed are generally taken as $1400-1500 \mathrm{rpm}$. On the basis of quantities, $I_{p}, n$, the peripheral speed, the external fan diameter, the meridional speed and coefficient is calculated in the following

\subsection{Design of axial flow fan (Modified design)}

Table 3.1 Requirement of Axial Flow Fan \& Input Parameter

\begin{tabular}{|c|c|c|}
\hline S. No. & Require & $\begin{array}{l}\text { Qua } \\
\text { ntity }\end{array}$ \\
\hline 1. & Air Flow (v) & $\begin{array}{c}7 \\
\mathrm{~m}^{3} / \mathrm{Se} \\
\mathrm{c}\end{array}$ \\
\hline 2. & $30^{\circ}$ to $50^{\circ}$ & \\
\hline 3. & Static Pressure & $\begin{array}{c}30 \\
\mathrm{mmw} \\
\mathrm{g}\end{array}$ \\
\hline 4. & $1450 \mathrm{rpm}$ & \\
\hline 5. & $0.8 \mathrm{~m}$ & \\
\hline 6. & $25 \mathrm{~m}$ & \\
\hline
\end{tabular}

We take External Diameter $\mathrm{d}_{2}$

Then we find Value $\varphi$

We find Value this Equation $\psi$

Take Equation of $\psi$

Then we find the value of

And Equation of

$$
\begin{aligned}
& d_{2}=\sqrt[3]{\left(\frac{240 V}{\pi^{2} \varphi n}\right) \psi} \\
& d_{2}=\frac{60}{\pi n} \sqrt{(2 \Delta \mathrm{P}) / \sqrt{(p)}}
\end{aligned}
$$$$
\psi=\frac{1}{\sigma^{2} \delta^{2}}
$$$$
\sigma=\frac{2.773}{\delta}
$$

$$
\varphi=\frac{1}{\sigma \delta^{3}}
$$


Equating both value $\psi$ and $\varphi$

Then Find Value o \& $\delta$

After the value speed coefficient and diameter coefficient is calculated, specific diameter $r$ is read from the

graph given in Figure

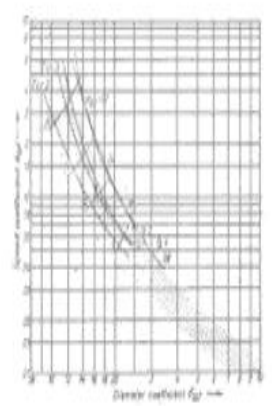

Fig. 3.1 Optimum curves with minimal hub ratios for different methods of Installation for

\section{impellers with low characteristics}

Specific speed coefficient

The meridional speed is obtained from

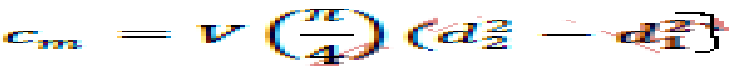

$$
\begin{aligned}
& x_{2}=\pi a_{2}=\operatorname{mon}
\end{aligned}
$$

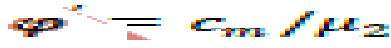

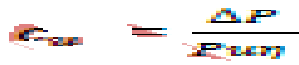

For $\mathrm{t} / \mathrm{l}$, the best value of which range selects the first value are being at the tip of the blade. Thus we have take number of blade $\mathrm{Z}$

$Z=(4 \pi / 1.5)\left[\sin \beta_{2} /\left\{1-\left(\mathrm{r}_{1} / \mathrm{r}_{2}\right)\right\}\right]$

Then obtain value of $\beta_{2}$ then we take value graph by Eck then we obtain value $\beta_{1}$

Then we obtain value s/l by fig. Weining Draw Velocity triangle

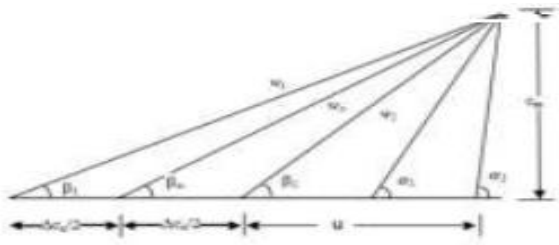

Fig.3.2: Velocity Diagram with Pre-rotation; Axial Outlet.

$$
\mathrm{c}_{\mathrm{m}}=\omega_{2} \sin \beta_{2}
$$

Then we obtain value of $w_{2}$ in $\mathrm{m} / \mathrm{s}$ and $\quad \mathrm{u}=\omega_{2} \cos \beta_{2}$

Then we obtain value of $u$ General relationship angle

Then we find value of $\beta_{\infty}$ And $\cot \beta_{\infty}=1 / 2\left(\cot \beta_{1}+\cot \beta_{2}\right) c_{m}=\omega_{\infty} \sin \beta_{\infty}$

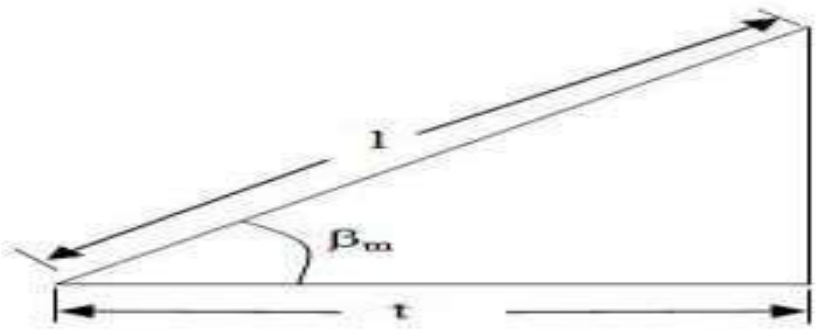

Fig.3.3: Distance of Tip and Length of Chord 
We find the value of $\omega_{\infty} \quad v_{\infty} / 2=\left(\beta_{2}-\beta_{1}\right) / 2 \quad \beta_{\mathrm{m}}=\left(\beta_{1}+\beta_{2}\right) / 2$

And value of $t / 1$

Then we take value of by graph $\mathrm{t}=1 \cos \beta_{\mathrm{m}}$ then take 1

And we take a value of $\mu$

And $(1-\mu) / \mu=$ value of this equation

And Value

We obtain value $\mathrm{v}$

$\Delta \beta=\Delta \beta_{1}(1 / t)^{2}$ according to Weining graph determining the increase of angle by profiling s, profile thickness , 1 chord length

$\Delta \beta=$ value of this equation

We take value of

$\beta_{\mathrm{m}}+\Delta \beta=$ value of this equation

\begin{tabular}{|c|c|c|c|}
\hline & \multicolumn{2}{|l|}{$\begin{array}{l}\text { Table3.2: Design data of the } \\
\text { fan }\end{array}$} & \\
\hline & & & \\
\hline Parameter & & Value of Existing & Value of Modified \\
\hline & & Design & Design \\
\hline $\mathrm{d} 2$ & & $775 \mathrm{~mm}$ & $795 \mathrm{~mm}$ \\
\hline $\mathrm{d} 1$ & & $230 \mathrm{~mm}$ & $225 \mathrm{~mm}$ \\
\hline$\beta_{1}{ }^{\circ}$ & & 25 & 30 \\
\hline$\beta_{2}{ }^{\circ}$ & & 45 & 50 \\
\hline $\mathrm{L}$ & & $85 \mathrm{~mm}$ & $85 \mathrm{~mm}$ \\
\hline$\mu$ & & 0.54 & 0.61 \\
\hline$v$ & & 8.51 & 6.393 \\
\hline & & 0.130 & 0.130 \\
\hline & & 0.22 & 0.22 \\
\hline $\mathrm{Cm}$ & & 16.13 & 15.32 \\
\hline $\mathrm{z}$ & & 2.16 & 2.16 \\
\hline & & 9 & 9 \\
\hline
\end{tabular}

\subsection{Experimental Setup}

To evaluate the air flow velocity with the standard measurement criterions by the help of Anemometer, test setup was developed as shown in fig (3.7) \& fig (3.8). A circular duct was placed at the fan side to evaluate the inlet air velocity. A rectangular duct was fitted at the exit end of the heat exchanger to find the velocity of the air leaving the heat exchanger. Duct Transverse method for air flow measurements for circular duct and rectangular duct was adopted.

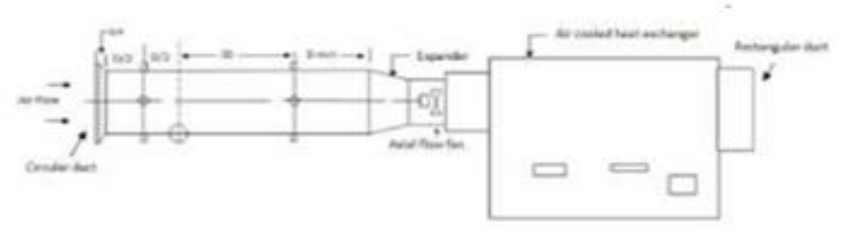

Fig 3.7: Block diagram of Experimental setup

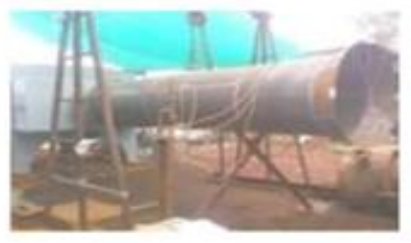

Fig.3.8: Experimental setup

Several test locations for the evaluation of velocity were set along the strings as marked as A, B and C in the fig. (2). Anemometers have traditionally been employed for air duct balancing. This cumbersome task requires performing a traverse of the opening, measuring and manually recording the velocity

\section{IV .Result And Discussion}

The fan of heat exchanger was designed and with modified dimension, the fan was fabricated and installed in heat exchanger. The modified fan was tested and the details of testing as given below:-

\subsection{Testing of fan velocity at different string $A, B$ and $C$.}

The experimental set up was developed to test the air flow velocity of the both the type of duct is circular duct at inlet and rectangular duct at the outlet. To take the data statistically, circular duct was divided in there to in to three parts string $\mathrm{A}, \mathrm{B}$ and $\mathrm{C}$ and each string is divided in six parts to the observation efficiency and statistically. The observation of three string A, B and C of air flow velocity have taken are presented in table no. 4.1 
Table 4.1: Air Flow Measurement On The Face Of the Duct By Duct Transverse Method For Circular Duct.

\begin{tabular}{|c|c|c|c|c|c|c|}
\hline Measuring & & & \multicolumn{2}{|c|}{ Velocity $(\mathrm{m} / \mathrm{s})$} & & \\
\hline \multicolumn{7}{|l|}{ Point } \\
\hline & \multicolumn{2}{|l|}{ String A } & \multicolumn{2}{|c|}{ String B } & \multicolumn{2}{|l|}{ String C } \\
\hline & Existing & Modified & Existing & Modified & Existing & Modified \\
\hline & Fan & Fan & Fan & Fan & Fan & Fan \\
\hline 1 & 12.1 & 14 & 12.2 & 14 & 13.2 & 15 \\
\hline 2 & 13 & 16.2 & 12.6 & 15.3 & 13.5 & 16.4 \\
\hline 3 & 12.5 & 15.1 & 11.6 & 14.8 & 12.3 & 15.6 \\
\hline 4 & 12.8 & 15.5 & 12.4 & 15.1 & 12.5 & 15.2 \\
\hline 5 & 12.8 & 16 & 12 & 15 & 14.5 & 16.5 \\
\hline 6 & 11.2 & 15 & 11 & 13.2 & 13.2 & 15.2 \\
\hline
\end{tabular}

\subsection{Calculation of Existing Fan}

Statics Pressure $(\Delta \mathrm{p})=20 \mathrm{mmwg}$

Total velocity of duct $=212.5 .9 \mathrm{~m} / \mathrm{s}$ For average velocity $=11.82 \mathrm{~m} / \mathrm{s}$

Air flow of the circular duct=A V F Where F=1 = 5.944 $\mathrm{m}^{3} / \mathrm{s}$ Say $6 \mathrm{~m}^{3} / \mathrm{s}$

\subsection{Calculation of Modified Fan}

Statics Pressure $(\Delta \mathrm{p})=20 \mathrm{mmwg}$

Total velocity of duct $=278.3 \mathrm{~m} / \mathrm{s}$ For average velocity

$=15.5 \mathrm{~m} / \mathrm{s}$ Air flow of the circular duct $=\mathrm{A} \mathrm{V} \mathrm{F}=7.69 \mathrm{~m}^{3} / \mathrm{s}$

The data show that in string A, the observation of air velocity at point 1 and 6 which are closed to the end of the duct varies from $12.1 \mathrm{~m} / \mathrm{s}$ and $11.2 \mathrm{~m} / \mathrm{s}$ in existing fan respectively, where as the point 1 and 6 in modified fan, the air flow velocity varies from $14 \mathrm{~m} / \mathrm{s}$ and $15 \mathrm{~m} / \mathrm{s}$ respectively. The velocity at the point 2 and 5 in the existing fan was observed $13 \mathrm{~m} / \mathrm{s}$ and $12 \mathrm{~m} / \mathrm{s}$ respectively where as in the modified fan, the air flow velocity at point 3 and 4 points the modified fan where as the air velocity in 2 and 4 points in modified fan was observed at the rate of $15.1 \mathrm{~m} / \mathrm{s}$ and $15.5 \mathrm{~m} / \mathrm{s}$ respectively, the average air flow velocity in the string A was observed in the existing fan the rate of $12.4 \mathrm{~m} / \mathrm{s}$ where as the average air flow velocity in the modified fan was observed at the rate of $15.26 \mathrm{~m} / \mathrm{s}$ which is desired one.

The string is also divided in six parts take the data statically to represent all the point of the duct and compared the air flow velocity of the duct of the existing fan and modified fan. The data were taken 1, 2,3,4,5 and 6 points. The point 1 and 6 are varying close to the end of the duct where as the point 2 and 5 are found in themiddle of the duct. The air in the existing fan was observed $12.2 \mathrm{~m} / \mathrm{s}$ and $11 \mathrm{~m} / \mathrm{s} \mathrm{respectively.} \mathrm{Where} \mathrm{as} \mathrm{the}$ at the point 1 and 6 is the modified fan was observed $14 \mathrm{~m} / \mathrm{s}$ and $13.2 \mathrm{~m} / \mathrm{s}$ respectively. The air flow rate at the point 2 and 5 in existing fan and modified fan was recorded as $13.6 \mathrm{~m} / \mathrm{s}$ and $12 \mathrm{~m} / \mathrm{s}$ in existing fan and 15.3 $\mathrm{m} / \mathrm{s}$ and $15 \mathrm{~m} / \mathrm{s}$ in modified fan. Similarly the air flow velocity rate in existing and modified fan at point 3 and 4 was found $11.6 \mathrm{~m} / \mathrm{s}, 12.4 \mathrm{~m} / \mathrm{s}$ and $14.8,15.1 \mathrm{~m} / \mathrm{s}$ respectively. The average velocity in string in the string B at all point the point in existing and modified fan are found $11.96 \mathrm{~m} / \mathrm{s}$ and $14.56 \mathrm{~m} / \mathrm{s}$ respectively.

The data of string $\mathrm{C}$ show that the observation of air velocity at measuring point 1 and 6 . Which are close to the end of the duct varies from $14.2 \mathrm{~m} / \mathrm{s}$ and $13.2 \mathrm{~m} / \mathrm{s}$ in existing fan respectively. Where as at point 1 and 6 in modified fan, the air flow varies from $15 \mathrm{~m} / \mathrm{s}$ and $15.2 \mathrm{~m} / \mathrm{s}$ respectively. The air flow rate at point 2 and 5 in existing fan and modified fan was observed as $13.5 \mathrm{~m} / \mathrm{s}$ and $14.5 \mathrm{~m} / \mathrm{s}$ in existing fan and $16.4 \mathrm{~m} / \mathrm{s}$ and 16.5 $\mathrm{m} / \mathrm{s}$ in modified fan. Similarly, the air flow velocity rate in existing and modified fan at point 3 and 4 was found $12.3 \mathrm{~m} / \mathrm{s}, 12.5 \mathrm{~m} / \mathrm{s}$ and $15.6 \mathrm{~m} / \mathrm{s}$ and $15.2 \mathrm{~m} / \mathrm{s}$ respectively.

The average velocity in string at all point the in existing and modified fan are found $13.2 \mathrm{~m} / \mathrm{s}$ and 15.6 $\mathrm{m} / \mathrm{s}$ respectively. The graphical optimization of value of air flow velocity was obtained of string $\mathrm{A}, \mathrm{B}$, and $\mathrm{C}$ of existing and modified fans. 

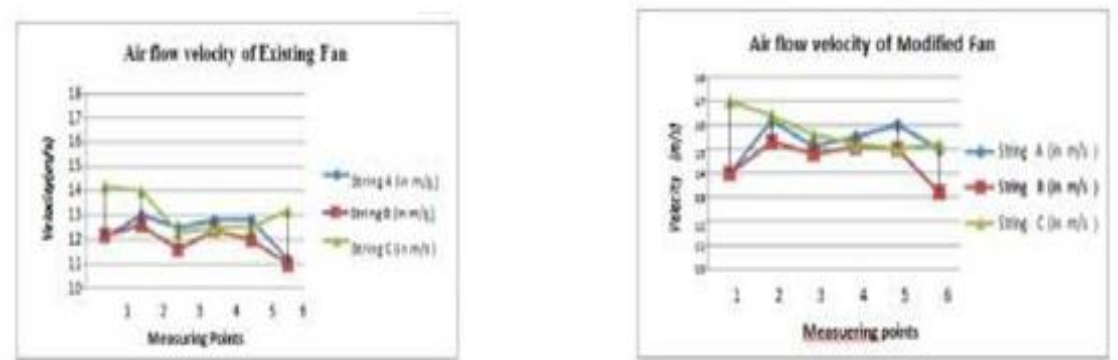

Fig. 4.1 : Velocity At Different Measuring Point At Circular At Duct Of Existing Fan . Fig. 4.2: Velocity At Different Measuring Point Circular Duct Of Modified Fan.

Showed that graph of modified fan the graph of modified fan of string A, B and C were imposed in one graph and it indicate that at point 3 and 4 all the three graph are meeting. Therefore it may be predicted that highest average velocity at point 3 and 4 is about $13 \mathrm{~m} / \mathrm{s}$.

If showed that modified fan has given average highest velocity at the range of $16 \mathrm{~m} / \mathrm{s}$ in comparison to the average highest velocity in existing fan is $13 \mathrm{~m} / \mathrm{s}$.

Testing of rectangular duct placed at outlet for testing of rectangular duct, the duct transversing method was used. The duct was divided horizontally to the Twelve parts is from $\mathrm{C} 1$ to $\mathrm{C} 12$ and in four parts vertically is $\mathrm{R} 1$ to get the result efficiently and may be verified statically.

Table 4.2: Air flow measurement on the face of the Duct by Duct Transverse method for rectangular duct of Existing Fan.

\begin{tabular}{|l|l|l|l|l|l|l|l|l|l|l|l|l|}
\hline $\begin{array}{c}\text { Test } \\
\text { point }\end{array}$ & $\mathrm{Cl}$ & $\mathrm{O}$ & $\mathrm{C}$ & $\mathrm{CA}$ & $\mathrm{C}$ & 6 & 07 & 08 & 0 & $\mathrm{C} 10$ & $\mathrm{Cl1}$ & $\mathrm{C12}$ \\
\hline
\end{tabular}

Avg. Velocity of Exiting fan at rectangular section $=140 / 48=$

$$
2.91 \mathrm{~m} / \mathrm{s}
$$

Air flow of the Rectangular duct $=\mathrm{A}$ V F Where $\mathrm{F}=1$

$$
=1.822 .91=5.3 \mathrm{~m}^{3} / \mathrm{s}
$$

Table 4.3: Air flow measurement on the face of the Duct by Duct Transverse method for rectangular duct of

\begin{tabular}{|l|l|l|l|l|l|l|l|l|l|l|l|l|}
\hline Test & C1 & C2 & C3 & C4 & C5 & C6 & C7 & C8 & C9 & C10 & C11 & C12 \\
\hline point & & & & & & & & & & & & \\
\hline R1 & 2.9 & 2.4 & 2.8 & 6.2 & 6.2 & 4.2 & 3 & 5.1 & 5.1 & 3.4 & 2.8 & 3.6 \\
\hline & & & & & & & & & & & & \\
\hline R2 & 1.7 & 3.2 & 3.2 & 6 & 3.9 & 1.8 & 0.5 & 2.8 & 4.2 & 4.5 & 2.5 & 3.3 \\
\hline & & & & & & & & & & & & \\
\hline R3 & 2.7 & 2.7 & 3.3 & 4.9 & 3.6 & 1.6 & 1.5 & 3.4 & 4.6 & 4.1 & 2.8 & 2.8 \\
\hline & & & & & & & & & & & & \\
\hline R4 & 3.9 & 3.5 & 3.8 & 5.3 & 5.3 & 4.3 & 5.4 & 5.8 & 7 & 3.2 & 2.4 & 2.7 \\
\hline
\end{tabular}

Avg. Velocity of Modified fan at rectangular section $=175.2 / 48=$

$$
3.65 \mathrm{~m} / \mathrm{s}
$$

Air flow of the Rectangular duct $=$ A V F Where $\mathrm{F}=1$

$$
\begin{aligned}
& =1.823 .65 \\
& =6.64 \mathrm{~m}^{3} / \mathrm{s}
\end{aligned}
$$




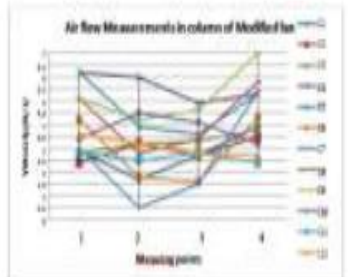

Fig.4.3: Velocity at different measuring point at rectangular duct in column wise of Modified fan.

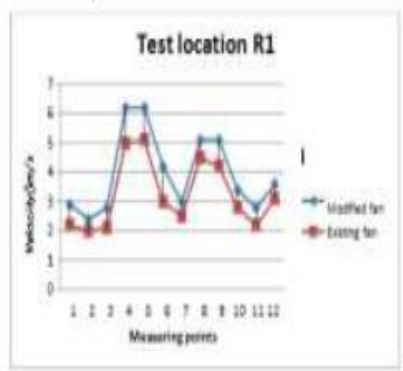

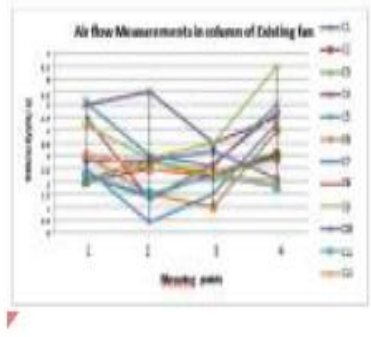

Fig.4.4:Velocity at different measuring point at rectangular duct in column wise of Existing fan.

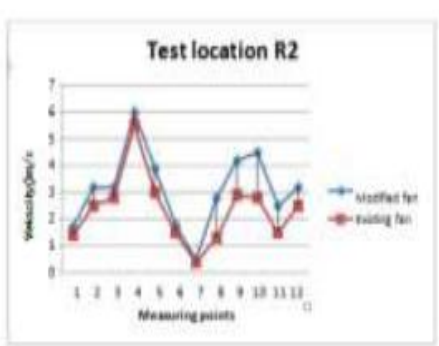

Fig.4.5: Velocity at different measuring point at row Rl. Fig.4.6: Velocity at different measuring point at row

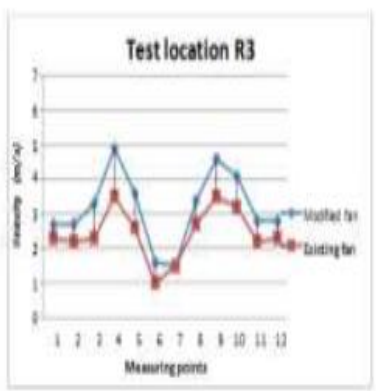

KL.

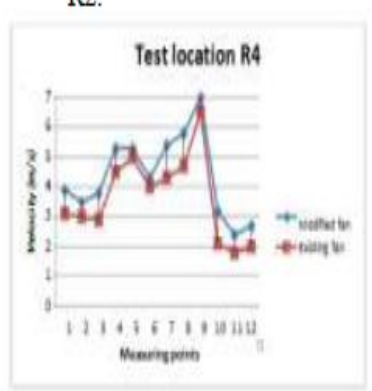

Fig.4.7: Velocity at different measuring point at row R3 Fig.4.8: Velocity at different measuring point at

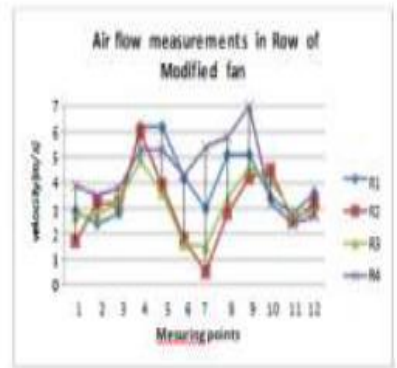

Fig.4.9: Velocity at different measuring point at rectangular duct in row wise of Modified fan row $\mathrm{R} 4$

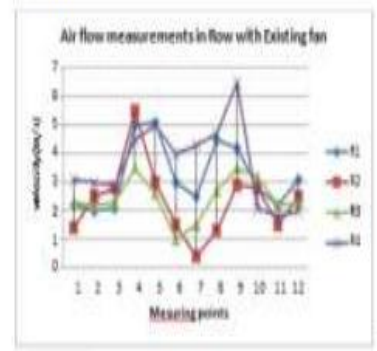

Fig.4.10: Velocity at different measuring point at rectangular duct in row wise of Existing fan. 
Test was conducted to take observation on rectangular duct of modified. The data from $\mathrm{C} 1$ to $\mathrm{C} 12$ at $\mathrm{R} 1$ varied from $2.4 \mathrm{~m} / \mathrm{s}$ to $6.2 \mathrm{~m} / \mathrm{s}$ and $1.7 \mathrm{~m} / \mathrm{s}$ to $6 \mathrm{~m} / \mathrm{s}$. The value of air flow velocity from $\mathrm{C} 1$ to $\mathrm{C} 12$ at R3 and $\mathrm{R} 4$ varied from $1.5 \mathrm{~m} / \mathrm{s}$ to $4.9 \mathrm{~m} / \mathrm{s}$ where as at R4 varied from $2.4 \mathrm{~m} / \mathrm{s}$ to $7 \mathrm{~m} / \mathrm{s}$. It show that maximum value of air flow velocity obtained at $\mathrm{C} 4$ and $\mathrm{C} 5$ with corresponding to R1 and R4.Similarly the test was conducted to take observation rectangular duct of modified fan. The data showed that from $\mathrm{C} 1$ to $\mathrm{C} 12$ at $\mathrm{R} 1$ point, the air flow velocity varied from $2 \mathrm{~m} / \mathrm{s}$ to $5.1 \mathrm{~m} / \mathrm{s}$. Where $1 \mathrm{~m} / \mathrm{s}$ to $3.2 \mathrm{~m} / \mathrm{s}$ and $2 \mathrm{~m} / \mathrm{s}$ to $5 \mathrm{~m} / \mathrm{s}$ respectively. The maximum value of air flow velocity at existing fan was obtained at $\mathrm{C} 4$ and $\mathrm{C} 5$ at corresponding to R1 is 5to 5.1 $\mathrm{m} / \mathrm{s}$. The data show that the maximum air flow velocity is obtained in the middle of the rectangular duct in Existing fan as well as modified fan.

\section{Conclusion \& Future Scope}

The data of air flow velocity in terms of bar diagram is presented in fig. 5.1. The result showed that the maximum volume of air flow rate is obtained in existing, required and modified fan are $5.994 \mathrm{~m}^{3} / \mathrm{s}, 7 \mathrm{~m}^{3} / \mathrm{s}$ and $7.65 \mathrm{~m}^{3} / \mathrm{s}$ respectively. The testing result showed that the cooling effect was obtained maximum with modified fan air flow volume $7 \mathrm{~m}^{3} / \mathrm{s}$.

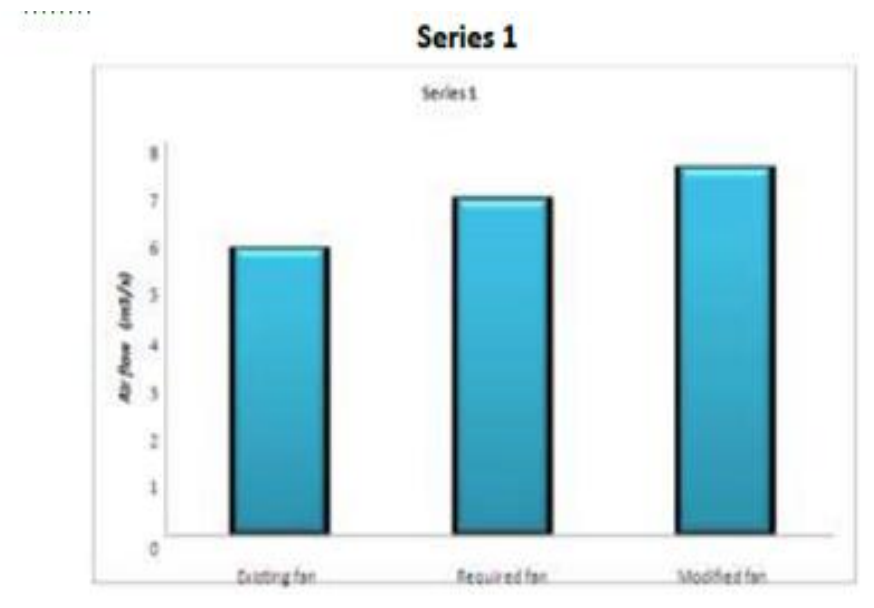

Fig .5.1: A bar chart of Air flow volume of Existing fan, required fan and modified fan.

\subsection{Future Scope}

In the present distribution work, the detailed design procedure for an axial flow fan of heat exchanger application has been presented experimental studies have also been performed for evaluating the performance of the axial flow fan and necessary modification for required air flow velocity is also carried out. The testing of the modified axial flow fan was done and desired air flow rate was obtained.In future some mathematical model may be developed for carrying out the performance evaluation of the axial flow fan and the result may be validated form the present experimental results. The optimization of axial air flow fan parameter may be done for the industrial use.

\section{References}

[1]. AlirezaFalahat[ISSN: 2045-7057],"Numerical and Experimental Optimization of Flow Coefficient in Tubeaxial Fan”, International Journal of Multidisciplinary science \& Engineering, Vol. 2, No. 5, Aug. 2011.

[2]. Oday I. Abdullah, Josef Schlattmann, "Stress Analysis of Axial Flow Fan”, Adv. Theory. Appl. Mech., Vol. 5, 2012, no. $6,263-275$.

[3]. MahajanVandana N.,* Shekhawat Sanjay P. "Analysis of Blade of axial flow fan using Ansys", International Journal of Advanced Engineering Technology E-ISSN 0976-3945.2012. 